\title{
Melancholic depression: between submission and voluntarism
}

\section{Opinion}

It is well known that melancholic depressed patients (not those who suffer from a temporary depression due to an objective loss) are often victims of subjugation and psychological violence on the part of their partners through blaming, frightening and moral terrorism with those who harass them, with the purpose of bend them and subject them to exploitation under the promise of recognizing them as subjects, if they bow their impositions. It should be noted that they are the same depressive patients who lend themselves to this game for fear of being abandoned and as a price they pay to obtain those vital crumbs of recognition.

From the obverse of this situation, we observe other elements not described by the psychoanalytic clinic of melancholy. And is that the melancholic patient, who is subjected and exploited, enters the relationship of couple with a secret weapon: $\mathrm{He} / \mathrm{she}$ has the ability to separate sexual desire from love and, he/she can perfectly love his partner without wishing him or, stay in a relationship without love and with some desire, but giving commitment in exchange for affection and recognition. He/she will be unfaithful with the imaginary characters of your fantasy, when he/she access or propose a sexual relationship with the imaginary placed in another scene. Already in his youthful sexual life the depressed patient enters into relationships where, from the outset, the infeasibility of love is assured (by the existence of a third person, by the impossibility of consummating the relationship, by agreed-upon agreements of non-commitment, etc.) and where only desire has a place. In other words, enter into relationships without being in love, just thinking about preventing annulment.

This originates in an Oedipal Complex in which the eroticized parent submitted with the same maneuvers as the partner chosen to be loved. He/she repeats the libidinal transfer with "aim" of the unconscious and, falls in love as one who "does not know" or does not want to see that, the chosen couple possesses the same characteristics as their oedipal object. And how incest is excluded by castration (the way it was given); the sexual relationship, with the substitute of the oedipal parent, is destined to fail. It is from this substitute that the depressed patient waits for the recognition that allows him to constitute himself as a subject; therefore, getting it is more important than wanting it or having your wish. The unconscious guilt for being unfaithful to "another" is resolved by the fracture between love and desire. The tenacity to remove with elegance and subtlety the desire of his partner is so methodically worked, that the sexual non-relationship is fully justified, even though physical intercourse exists even if only as a bad encounter.

The subjective position of the melancholic patient is that of a distrustful person before the law: "Why trust someone's word, if I can be abandoned?" That is, the oedipal resolution of these patients was the following: 'I allow myself to do what that I am pleased, while I comply with the conditions and the blackmail that they imposed on me, that or those who give recognition.' The result of that attitude so characteristic in the melancholic patients, will be that of extreme fear/guilt to confront their oppressors; at the same time that they exercise a voluntarism without cessation in everything that is about

\author{
Volume 5 Issue 3 - 2018
}

\author{
Fernando Arce Hochkofler ${ }^{1,2}$ \\ 'DEA de Psychanalyse, Université Paris VIII, France \\ ${ }^{2}$ Psychoanalyst in La Paz, Bolivia
}

Correspondence: Fernando Arce Hochkofler, DEA de Psychanalyse, Université Paris VIII,Vincennes-Saint Denis, France, Psychoanalyst in La Paz, Bolivia, Email ferahoch@hotmail.com

Received: May 0I, 2018 | Published: May 15, 2018

getting away with theirs, with a rebellious character that borders on existential cynicism. Their will is focused on obtaining recognition, through over-performance (work and/or domestic) real achievements to meet the conditions imposed by the one that grants recognition and with which it establishes an ambivalent relationship of emotional codependence. For the moral harasser does not know that he is a slave to his own fear of object loss and believes that the subjection of the other will be forever. He does not know that only circumstantially takes advantage of a "generous" delivery, and then come the settling of accounts, revenge for being a deaf, indolent and selfish couple. The depressive will represent how much he gave in the relationship trying to get crumbs of recognition and how much he just received, showing a debt that is paid with the currency of betrayal, contempt and / or abandonment.

It happens that in the origin of the depressive structure we invariably find a history of affective abandonment in the form of any disturbance of the emotional support that parents must grant the newborn until their five years old. The troubles can goes from the rejection, the abandonment, the early disappearance, the discrimination and until the lowering as a blamed object. This child, who will be a future depressed patient, suffers affective abandonment during the critical and constituent period as a subject, as long as it is not recognized as an object / cause of his parents' desire. This abandonment coincides with the first stages of his libidinal development (oral, vocal, scopic, anal and phallic). As the operation of recognition is re-edited in the critical periods of development (pre-oedipal drive, oedipal, puberty and adolescence), all its psychic structure suffers a lack of stowage or anchoring that renders the subject lightweight in its identifications, easy to leave, loose body to abandon their libidinal relationships and, extremely dependent on the recognition of the Other. This lack of consistency, this structural weakness that renders cowards to melancholics patients; it leads them to project on the hologram of their double, their anguish of recognition; whether they propose it as a character (one of theatre or one of ego just for social recognition) and/ or hallucinate as an identical that comes to supplant them, a double in the narcissistic sense, whose emergence triggers an uncontrollable anguish.

Hence, the usual symptoms presented by the depressive patients are two: an anguish of object loss that occurs with attacks of anxiety, fear and anger at the risk of losing their libidinal objects displaying oral mechanisms of cannibalistic introjection (bulimia/anorexia) and, 
anal obsessive retention and control with; an extreme dependence on the Other that grants recognition, which deals with ambivalent mechanisms in the relationship with his sexual partner, namely: of submission versus rebellion, of over-performance versus reluctance, of excessive credulity in his word (hypnotic reactions to his voice) versus distrust in their being, of unconditional fidelity versus "dosage" in affective surrender; trying to avoid their cancellation as subjects.

As is logical, this pathological link of the melancholic patient with the other, will result in an attitude of cynical nihilism in relation to everything that is institutional (such as marriage, the Church, the state, etc.) and, in an inability to believe in the other, because he attributes the same intentionality with which he gives his freedom to his oppressors: "What does this other who wants to give me his love with free?" His distrust of love is extended to God as if he said: "I only believe in what I do to get recognition, I do not think anyone loves me for myself because I think I am unworthy of being loved."

\section{Acknowledgements}

None.

\section{Conflict of interest}

The author declares no conflict of interest. 